\title{
Structural and electronic properties of $\mathrm{SnO}_{2}$ doped with non-metal elements
}

\author{
Jianyuan $\mathrm{Yu}^{1,2,3}$, Yingeng Wang ${ }^{1}$, Yan Huang ${ }^{2,3}$, Xiuwen Wang ${ }^{2,3}$, Jing Guo ${ }^{3,4}$, \\ Jingkai Yang ${ }^{*} 1,5$ and Hongli Zhao ${ }^{*} 1,5$
}

\author{
Full Research Paper \\ Address: \\ ${ }^{1}$ College of Materials Science and Engineering, Yanshan University, \\ Qinhuangdao 066004, China, ${ }^{2}$ Department of Environmental and \\ Chemical Engineering, Tangshan University, Tangshan, Hebei \\ 063000, China, ${ }^{3}$ Graphene Application Technology Tangshan Public \\ Service Platform, Tangshan, Hebei 063000 , China, ${ }^{4}$ School of Civil \\ Engineering, Tangshan University, Tangshan, Hebei 063000, China \\ and ${ }^{5}$ State Key Laboratory of Metastable Materials Science and \\ Technology, China \\ Email: \\ Jingkai Yang* - yangjk@ysu.edu.cn; Hongli Zhao* - \\ zhaohongli@ysu.edu.cn \\ * Corresponding author \\ Keywords: \\ density functional theory (DFT); doped $\mathrm{SnO}_{2}$; electronic structure; \\ optical properties \\ Beilstein J. Nanotechnol. 2020, 11, 1321-1328. \\ https://doi.org/10.3762/bjnano.11.116 \\ Received: 02 June 2020 \\ Accepted: 09 August 2020 \\ Published: 03 September 2020 \\ Associate Editor: P. Leiderer \\ (C) 2020 Yu et al.; licensee Beilstein-Institut. \\ License and terms: see end of document.
}

\begin{abstract}
Crystal structure and electronic properties of $\mathrm{SnO}_{2}$ doped with non-metal elements $(\mathrm{F}, \mathrm{S}, \mathrm{C}, \mathrm{B}$, and $\mathrm{N})$ were studied using first-principles calculations. The theoretical results show that doping of non-metal elements cannot change the structure of $\mathrm{SnO}_{2}$ but result in a slight expansion of the lattice volume. The most obvious finding from the analysis is that F-doped $\mathrm{SnO}_{2}$ has the lowest defect binding energy. The doping with $\mathrm{B}$ and $\mathrm{S}$ introduced additional defect energy levels within the forbidden bandgap, which improved the crystal conductivity. The Fermi level shifts up due to the doping with $\mathrm{B}, \mathrm{F}$, and $\mathrm{S}$, while the Fermi level of $\mathrm{SnO}_{2}$ doped with $\mathrm{C}$ or $\mathrm{N}$ has crossed the impurity level. The Fermi level of F-doped $\mathrm{SnO}_{2}$ is inside the conduction band, and the doped crystal possesses metallicity. The optical properties of $\mathrm{SnO}_{2}$ crystals doped with non-metal elements were analyzed and calculated. $\mathrm{The} \mathrm{SnO}_{2}$ crystal doped with F had the highest reflectivity in the infrared region, and the reflectance of the crystals doped with N, C, S, and B decreased sequentially. Based on this theoretical calculations, F-doped $\mathrm{SnO}_{2}$ is found to be the best photoelectric material for preparing low-emissivity coatings.
\end{abstract}

\section{Introduction}

Thin film solar cells are devices that convert solar energy into electrical energy. Transparent conductive films (TCFs) are a thin film material with both conductive capabilities and high transmittance in the visible light range (300-800 nm) [1-3]. TCFs serve as the front electrode of thin film solar cells. Up to now, the solar energy conversion efficiency is about $23.3 \%$ [4], 
and it is important to increase the photovoltaic power generation efficiency, as well as the performance of the front electrode.

The intrinsic semiconductor $\mathrm{SnO}_{2}$ is not conductive due to the absence of free carriers. However, the bandgap of $3.6 \mathrm{eV}$ of $\mathrm{SnO}_{2}$ makes it a potentially ideal material for transparent electrode films. It had been proved that the doping of heteroatoms to replace $\mathrm{Sn}$ or O can lead to more carriers or holes. Therefore, extensive research works has been done examining different doping elements. Doped tin oxide thin film have been widely used in the fields of thin film solar cell electrodes, electronic display devices, and gas sensors. Also doped $\mathrm{SnO}_{2}$ been used for energy-saving low-emissivity glass coatings due to low resistivity, high transmittance of visible light, good thermal stability, acid-base corrosion resistance, high material hardness, and easiness of preparation processes [5]. Non-metal atoms, such as fluorine (F) and nitrogen $(\mathrm{N})$, were proved to be proper elements for doping. After doping with heteroatoms, the preferred orientation, optical properties, and electrical properties of $\mathrm{SnO}_{2}$ film are improved.

Analysis of the electrical properties of $\mathrm{SnO}_{2}$ films doped with different non-metal elements showed that the resistance of $\mathrm{SnO}_{2}$ films doped with $\mathrm{N}$ was higher [6-8] than that of $\mathrm{SnO}_{2}$ doped with other elements. Nguyen successfully prepared p-type $\mathrm{N}$-doped $\mathrm{SnO}_{2}$ films using magnetron sputtering [9]. The results show that the $\mathrm{SnO}_{2}$ films were n-type semiconductors, and the concentration of free carriers in the film increased as the temperature for sedimentation increased. Also, p-type semiconductors were successfully prepared from $\mathrm{N}$-doped $\mathrm{SnO}_{2}$ films. Through Al/N co-doping, a p-type $\mathrm{SnO}_{2}$ semiconductor thin film with excellent electrical properties was prepared. The resistivity, hole concentration and hole mobility were $7.1 \times 10^{-3} \Omega \cdot \mathrm{cm}, 6.24 \times 10^{19} \mathrm{~cm}^{-3}$ and $14.1 \mathrm{~cm}^{2} \cdot \mathrm{V}^{-1} \cdot \mathrm{s}^{-1}$, respectively [8]. Doping $\mathrm{SnO}_{2}$ with $\mathrm{F}$ (substituting O) can effectively increase the carrier concentration and improve the conductivity. Majumder successfully prepared $\mathrm{SnO}_{2}: \mathrm{F}$ thin films using spray pyrolysis with $\mathrm{SnF}_{2}$ as the precursor. By adjusting the concentration of the precursor solution, doped $\mathrm{SnO}_{2}$ films with different properties were obtained. When the concentration of the precursor solution was adjusted to $0.15 \mathrm{M}$ and the substrate temperature was $773 \mathrm{~K}$, a film with a resistivity of $1.2 \times 10^{-4} \Omega \cdot \mathrm{cm}$ was obtained [10]. Theoretical calculations, based on first principles, show that the doping of $\mathrm{N}$ into the $\mathrm{SnO}_{2}$ crystal structure can introduce oxygen vacancies, and thus, increase the charge density of the Sn sites. The replacement of $\mathrm{O}$ with $\mathrm{N}$ can simultaneously decrease the release of $\mathrm{CO}_{2}$.
While there are reports on experiments regarding the doping of $\mathrm{SnO}_{2}$ with non-metal elements, the mechanism of the effect of non-metal element doping on the performance of $\mathrm{SnO}_{2}$ is not yet clear. In recent years, many researchers used first-principles calculations to scrutinize the doping of $\mathrm{SnO}_{2}$ with non-metal elements such as F [11,12] and S [13]. The results show that the optical and electrical properties of $\mathrm{SnO}_{2}$ thin films can be changed by doping with different elements. However, the calculation conditions used in these works are uniform, so it is difficult to compare the effects of different doping elements. Also, some results are even inconsistent. We selected several nonmetal atoms (N, C, B, F, and S) with an atomic radius similar to that of $\mathrm{O}$ to dope $\mathrm{SnO}_{2}$. The calculations were carried out with the CASTEP software. In this paper, density functional theory (DFT) is used to analyze electronic structure and optical properties of $\mathrm{SnO}_{2}$ doped with non-metal elements.

\section{Crystal Structure Model and Calculation Method}

The $\mathrm{SnO}_{2}$ crystal has a tetragonal structure with space group $\mathrm{P}_{2} / \mathrm{mnm}$. There are six $\mathrm{O}^{2-}$ ions as nearest neighbors of each $\mathrm{Sn}^{4+}$ site, and three $\mathrm{Sn}^{4+}$ ions as nearest neighbors of each $\mathrm{O}^{2-}$ ion. Hence, the coordination numbers for $\mathrm{Sn}$ and $\mathrm{O}$ are six and three, respectively. The CASTEP package was used to construct a $3 \times 2 \times 1 \mathrm{SnO}_{2}$ supercell. To study the effect of non-metal element doping on the structure of $\mathrm{SnO}_{2}, \mathrm{~N}, \mathrm{C}, \mathrm{B}, \mathrm{F}$, or S was used to replace one $\mathrm{O}$ atom in the supercell. The model diagram of doped $\mathrm{SnO}_{2}$ is shown in Figure 1.

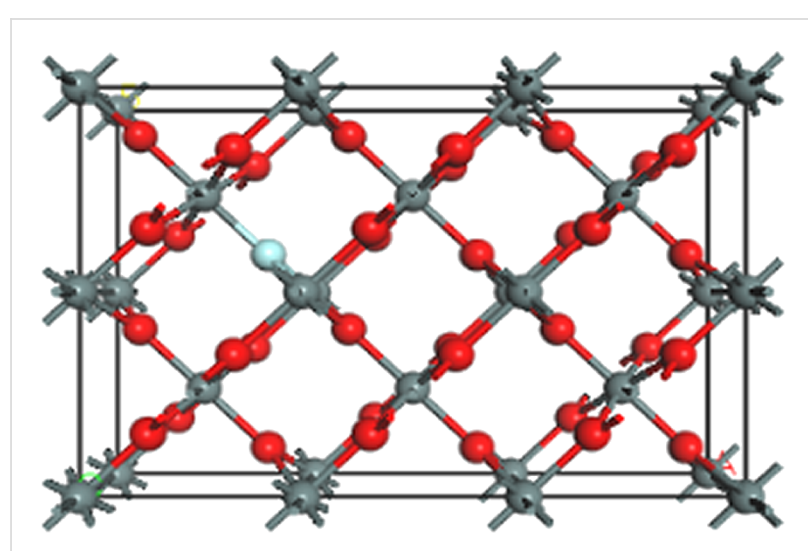

Figure 1: Schematic diagram of the structure of a non-metal atom replacing an $\mathrm{O}$ atom in $\mathrm{a} \mathrm{S} O_{2}$ unit cell (The red spheres are oxygen atoms, the gray spheres are tin atoms, and the light blue sphere is the non-metal atom).

The crystal structure optimization and electronic structure of the doped $\mathrm{SnO}_{2}$ cell were obtained through the CASTEP program based on DFT. The Perdew-Burke-Ernzerhof (PBE) generalized gradient approximation (GGA) was selected as the exchange-correlation functional. The interaction between inner 
electrons and valence electrons was described by the OTFG ultra-soft pseudopotential.

The valence electronic configuration in the system are $\mathrm{Sn}$ $5 \mathrm{~s}^{2} 5 \mathrm{p}^{2}, \mathrm{O} 2 \mathrm{~s}^{2} 2 \mathrm{p}^{4}, \mathrm{~N} 2 \mathrm{~s}^{2} 2 \mathrm{p}^{3}, \mathrm{C} 2 \mathrm{~s}^{2} 2 \mathrm{p}^{2}$, B $2 \mathrm{~s}^{2} 2 \mathrm{p}^{1}$, and F $2 \mathrm{~s}^{2} 2 \mathrm{p}^{6}$, $\mathrm{S} 3 \mathrm{~s}^{2} 3 \mathrm{p}^{4}$. The calculation parameters of the doping system were as follows: The plane waves cut-off energy is $571.4 \mathrm{eV}$, the Brillouin zone $k$-space was divided by $2 \times 3 \times 8$, the convergence accuracy of each atom was $10^{-5} \mathrm{eV} /$ atom, the internal stress between atoms was less than $0.05 \mathrm{GPa}$, and the atom displacement was less than $0.0001 \mathrm{~nm}$.

\section{Results and Discussion Structural optimization}

Table 1 shows the results of geometric optimization of the crystal structure of $\mathrm{SnO}_{2}$ doped with non-metal elements. After replacing one $\mathrm{O}$ atom in $\mathrm{SnO}_{2}$, the crystal structure is distorted and the volume expands. The atomic radius of $\mathrm{S}$ is much larger than that of the other doping atoms resulting in a volume expansion of $8.315 \%$. The lattice expansion rate also decreases in the sequence $\mathrm{B}>\mathrm{C}>\mathrm{N}$. However, the F-doped $\mathrm{SnO}_{2}$ has a larger volume expansion. Therefore, it is necessary to analyze the bond formation before and after $\mathrm{F}$ atom doping, as shown in Table 2. The population value is usually used to present the bonding characteristics of crystals. In general, a strong covalent bond shows a high population value, while a strong ionic bond is characterized by a low value. The results in Table 2 reveal that after doping with heteroatoms, the population value of the $\mathrm{Sn}-\mathrm{O}$ bond decreased, indicating that it to be more ionic. The population value of the Sn-F chemical bond is the lowest with only 0.125 , showing strong iconicity, obvious electron localization, and a high electron affinity. The chemical bonds of other elements $(\mathrm{C}, \mathrm{B}, \mathrm{N})$ and $\mathrm{Sn}$ elements exhibit the characteristics of covalent bonds. Therefore, $\mathrm{SnO}_{2}$ doped with $\mathrm{F}$ element exhibits an abnormal lattice expansion rate.

Therefore, there are surplus electrons in F-doped $\mathrm{SnO}_{2}$ crystals. The average net charge of $\mathrm{SnO}_{2}$ before and after doping is also presented in Table 2. Except for $\mathrm{N}$, which has a similar charge as $\mathrm{O}$, other doping elements all have a lower charge. Especially, for fluorine and boron, the charge values were only half of that of oxygen. This indicates again that the doping of fluorine and boron elements can provide more surplus electrons to the system.

To evaluate the stability of the crystal structure of the doped lattice, it is necessary to calculate the defect binding energy of the lattice. It can be calculated according to Equation 1 [13]:

$$
E_{\text {bind }}=\left(E_{(\mathrm{AB})}-E_{(\mathrm{A})}-E_{(\mathrm{B})}\right) / n \text {. }
$$

\begin{tabular}{|c|c|c|c|c|c|c|}
\hline & pure $\mathrm{SnO}_{2}$ & $\mathrm{SnO}_{2} / \mathrm{B}$ & $\mathrm{SnO}_{2} / \mathrm{C}$ & $\mathrm{SnO}_{2} / \mathrm{N}$ & $\mathrm{SnO}_{2} / \mathrm{F}$ & $\mathrm{SnO}_{2} / \mathrm{S}$ \\
\hline$a(\AA)$ & 9.47454 & 9.74866 & 9.68215 & 9.66020 & 9.70223 & 9.74767 \\
\hline$b(\AA)$ & 3.18638 & 3.24372 & 3.24956 & 3.24402 & 3.25942 & 3.25763 \\
\hline$c(\AA)$ & 14.2118 & 14.6574 & 14.5507 & 14.4901 & 14.5451 & 14.6390 \\
\hline$V\left(\AA^{3}\right)$ & 429.048 & 463.456 & 457.802 & 454.088 & 459.934 & 464.725 \\
\hline$\Delta V(\%)$ & - & 8.02 & 6.702 & 5.836 & 7.1987 & 8.315 \\
\hline
\end{tabular}

Table 2: Bond length and charge of the crystal structure with a non-metal atom replacing an $\mathrm{O}$ atom.

\begin{tabular}{|c|c|c|c|c|c|c|c|}
\hline & \multicolumn{4}{|c|}{ average bond length $(\AA)$} & \multicolumn{3}{|c|}{ average net charge $(e)$} \\
\hline & $\mathrm{Sn}-\mathrm{O}$ & population value & $\mathrm{Sn}-\mathrm{M}$ & population value & Sn & $\mathrm{O}$ & $\mathrm{M}$ \\
\hline $\mathrm{SnO}_{2}$ & 2.054 & 0.505 & - & - & 2.07 & -1.04 & - \\
\hline $\mathrm{SnO}_{2} / \mathrm{F}$ & 2.096 & 0.472 & 2.289 & 0.125 & 1.9 & -0.967 & -0.58 \\
\hline $\mathrm{SnO}_{2} / \mathrm{S}$ & 2.099 & 0.499 & 2.427 & 0.705 & 1.907 & -0.966 & -0.67 \\
\hline $\mathrm{SnO}_{2} / \mathrm{C}$ & 2.095 & 0.5 & 2.186 & 0.885 & 1.918 & -0.967 & -0.75 \\
\hline $\mathrm{SnO}_{2} / \mathrm{B}$ & 2.099 & 0.484 & 2.324 & 0.905 & 1.895 & -0.964 & -0.56 \\
\hline $\mathrm{SnO}_{2} / \mathrm{N}$ & 2.091 & 0.496 & 2.105 & 0.695 & 1.964 & -0.967 & -0.95 \\
\hline
\end{tabular}


$E_{(\mathrm{AB})}$ is the total energy of the doped structure, $E_{(\mathrm{A})}$ and $E_{(\mathrm{B})}$ are the chemical potentials of the atoms, and $n$ is the total number of atoms in the unit cell structure. The total energy and binding energy of the doped structure are shown in Table 3 .

The defect binding energy values of the doped systems (Table 3) are all negative, illustrating that all the doped crystal structures are stable structures. The defect binding energy decreases in the order of $\mathrm{B}, \mathrm{S}, \mathrm{C}, \mathrm{N}$, and $\mathrm{F}$. The $\mathrm{SnO}_{2}$ doped with $\mathrm{F}$ has the lowest binding energy, which makes it the most stable structure.

\section{Band structure and density of states}

After doping not only the crystal structure is distorted, but also the electronic structure of the $\mathrm{SnO}_{2}$ crystal is changed. The doping atoms introduce impurity levels in the bandgap of $\mathrm{SnO}_{2}$. The $\mathrm{SnO}_{2}$ crystal shows metallicity when the introduction of non-metal atoms causes the Fermi level to enter the conduction band. The electronic structure including the energy band structure, total density of states and partial wave state density of the doped system are shown in Figure 2.

For $\mathrm{SnO}_{2}$, the Fermi energy level is at the top of the valence band, indicating that the conductivity of $\mathrm{SnO}_{2}$ is low. The conduction band minimum (CBM) and the valence band maximum (VBM) are located at the same $\mathrm{G}$ point, which is consistent with the calculation results $[14,15]$ indicating that $\mathrm{SnO}_{2}$ is a direct bandgap semiconductor. In this work, the calculated bandgap is $1.28 \mathrm{eV}$, which is consistent with previous calculation results [16-18]. However, the bandgap is lower than the experimental value of $3.6 \mathrm{eV}$ [19], which is caused by the underestimation of the cross-correlation energy by the GGA function.

The energy of Sn $5 \mathrm{~s}$ orbits and the interaction between $\mathrm{Sn} 5 \mathrm{~s}$ and $\mathrm{O} 2 \mathrm{p}$ orbitals are overestimated, resulting in a wider valence band and narrower bandgap. The changes of bandgap and energy band cannot affect the electronic structure analysis of $\mathrm{SnO}_{2}$ crystals. The bandgap value can be modified by the complex variable function method $(\mathrm{DFT}+\mathrm{U})[20]$ to obtain a more accurate bandgap value. Although there are still some issues needed to be solved with this method, it is sufficient to mainly discuss the photoelectric properties of doped $\mathrm{SnO}_{2}$.

The total density of states of the $\mathrm{SnO}_{2}$ crystal shown in Figure 2 illustrates the that valence band of the system is divided into two parts, one from -19.1 to $-14.9 \mathrm{eV}$ and one between -8.1 and $0 \mathrm{eV}$. According to the density of partial wave states, the contributions to the deep energy level are from $\mathrm{Sn} 5 \mathrm{~s}$ and $\mathrm{O} 2 \mathrm{~s}$, orbitals while the shallow energy level mainly consists of $\mathrm{O} 2 \mathrm{p}$ and $\mathrm{Sn} 5 \mathrm{~s}$ orbitals with partial contribution of Sn $5 \mathrm{p}$ orbitals. The shallow energy level (from -8.1 to $-5.8 \mathrm{eV}$ ) is mainly due to $\mathrm{Sn} 5 \mathrm{~s}$ orbitals, and the $\mathrm{O} 2 \mathrm{p}$ orbital is responsible for the part between -5.8 and $0 \mathrm{eV}$. The main contributions to the conduction band are from $\mathrm{Sn} 5 \mathrm{~s}$ and $\mathrm{Sn} 5 \mathrm{p}$ orbitals.

It is worth noting that the energy band of $\mathrm{SnO}_{2}$ changes significantly after doping. B 2p, C 2p, S 3p, and N 2p orbitals appear in the $\mathrm{SnO}_{2}$ bandgap. $\mathrm{B}, \mathrm{F}$ and $\mathrm{S}$ cause the Fermi level of the doped crystal to move up. B and $\mathrm{S}$ introduce impurity levels in the $\mathrm{SnO}_{2}$ bandgap, which enhances the conductivity of the $\mathrm{SnO}_{2}$ crystal. The doping with $\mathrm{B}$ leads to more impurity levels in the forbidden band of $\mathrm{SnO}_{2}$, and the bandgap changes clearly, indicating that doping $\mathrm{B}$ atoms can adjust the $\mathrm{SnO}_{2}$ bandgap value well.

It can be seen from the partial wave state density diagram that the B $2 p$ orbital and the $\mathrm{S} 3 \mathrm{p}$ orbital enter the $\mathrm{SnO}_{2}$ crystal bandgap. After the introduction of $\mathrm{F}$ atoms, the Fermi energy level passes through the conduction band of $\mathrm{SnO}_{2}$ crystal, and $\mathrm{SnO}_{2}$ becomes a conductor. The energy band structure of $\mathrm{SnO}_{2}$ doped with $\mathrm{C}$ and $\mathrm{N}$ shows that the Fermi level crosses the impurity level and the conductivity of $\mathrm{SnO}_{2}$ semiconductor is enhanced. To sum up, it can be seen that doping with F can enhance the conductivity of $\mathrm{SnO}_{2}$ crystals effectively.

In order to obtain information about charge transfer after doping, the secondary differential charge distribution of the elements was calculated and the results are shown in Figure 3. Compared with $\mathrm{O}$, the ability of the doping atoms to accumu-

Table 3: Binding energy of $\mathrm{SnO}_{2}$ with an $\mathrm{O}$ atom substituted by a non-metal element.

\begin{tabular}{llll} 
& total energy $(\mathrm{eV})$ & concentration (atom \%) & binding energy (eV) \\
\hline $\mathrm{SnO}_{2} / \mathrm{F}$ & $-3.55 \times 10^{4}$ & 4.17 & -5.38 \\
$\mathrm{SnO}_{2} / \mathrm{S}$ & $-3.52 \times 10^{4}$ & 4.17 & -5.24 \\
$\mathrm{SnO}_{2} / \mathrm{C}$ & $-3.50 \times 10^{4}$ & 4.17 & -5.27 \\
$\mathrm{SnO}_{2} / \mathrm{B}$ & $-3.49 \times 10^{4}$ & 4.17 & -5.22 \\
$\mathrm{SnO}_{2} / \mathrm{N}$ & $-3.51 \times 10^{4}$ & 4.17 & -5.33
\end{tabular}




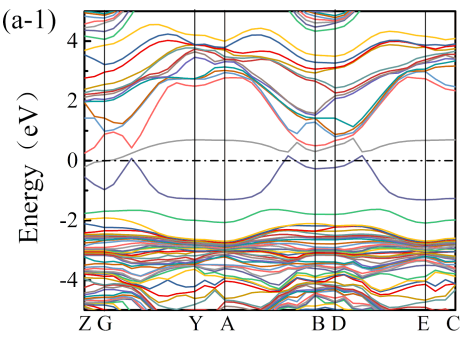

(b-1)
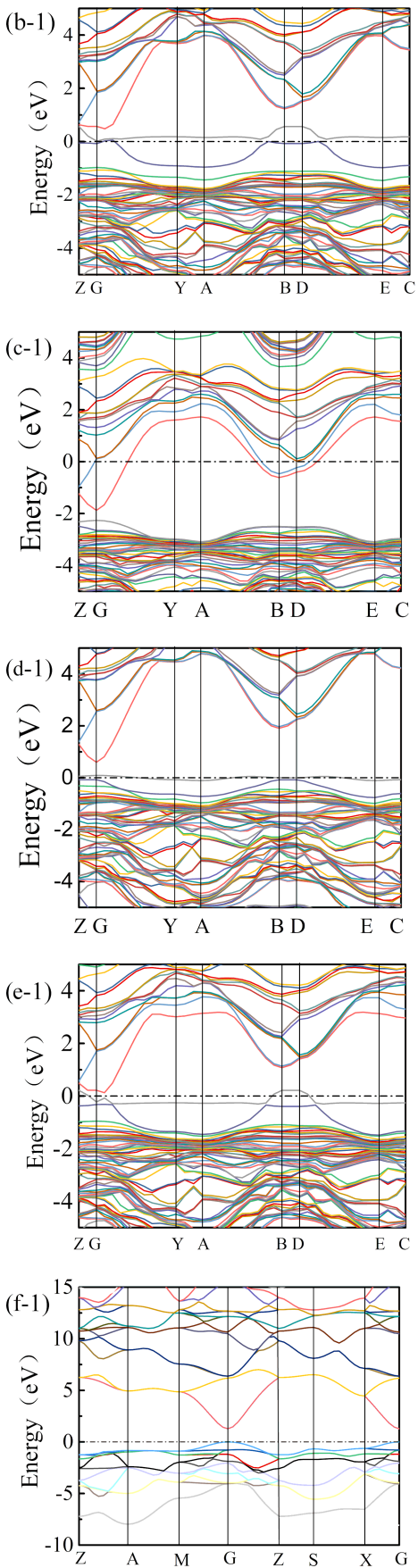
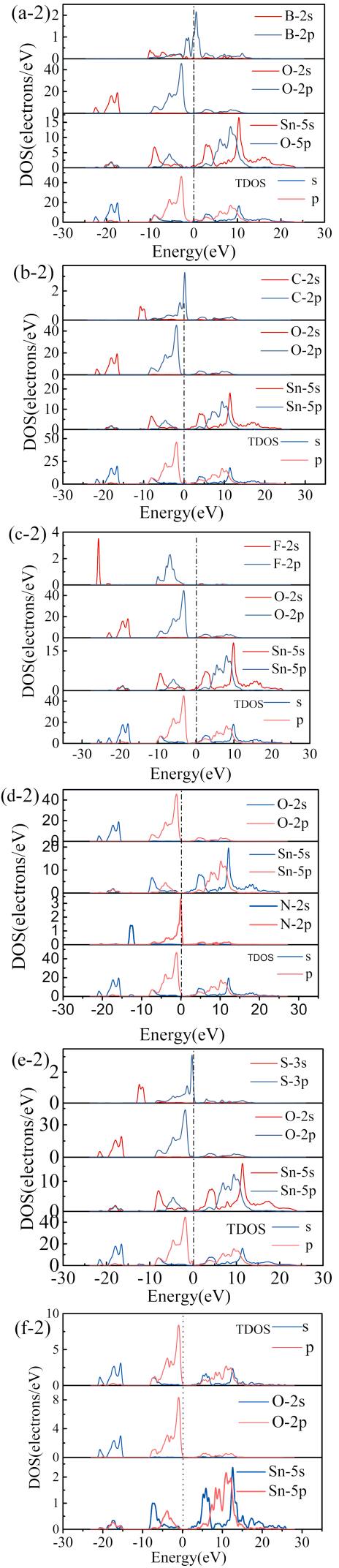

Figure 2: Energy band structure, total density of states and partial density of states of $\mathrm{SnO}_{2}$ doped with non-metal atoms: (a) $\mathrm{SnO} / \mathrm{B}$, (b) $\mathrm{SnO} / \mathrm{C}$, (c) $\mathrm{SnO}_{2} / \mathrm{F}$, (d) $\mathrm{SnO}_{2} / \mathrm{N}$, (e) $\mathrm{SnO}_{2} / \mathrm{S}$, (f) $\mathrm{SnO}_{2}$ 


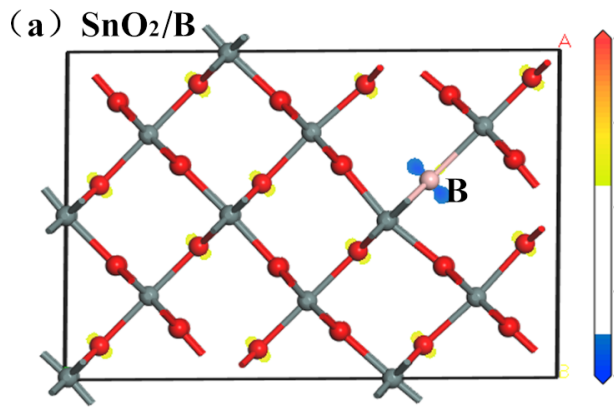

$7.840 \mathrm{e}-1$

$5.224 \mathrm{e}-1$

$-2.608 \mathrm{e}-1$

$-8.204 \mathrm{e}-4$

$-2.624 \mathrm{e}-1$

\section{(b) $\mathrm{SnO}_{2} / \mathrm{C}$}

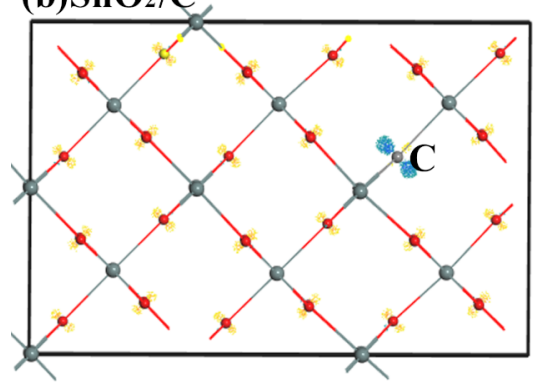

$7.742 \mathrm{e}-1$

$3.946 \mathrm{e}-1$

$1.501 \mathrm{e}-2$

$-3.646 \mathrm{e}-1$

$7.402 \mathrm{e}-1$

4.981e-1

$2.559 \mathrm{e}-1$

$1.375 \mathrm{e}-2$

$-2.284 \mathrm{e}-1$

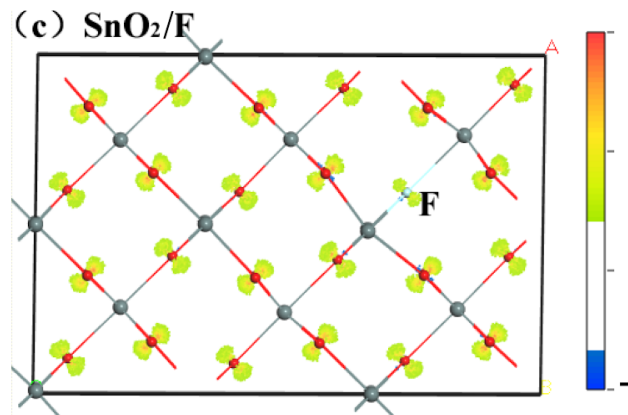

$8.032 \mathrm{e}-1$

$4.403 \mathrm{e}-1$

$7.749 \mathrm{e}-2$

$-2.853 \mathrm{e}-1$ (d) $\mathrm{SnO}_{2} / \mathrm{N}$

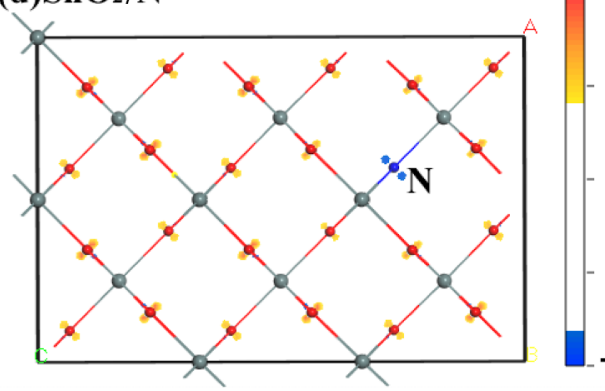

(e) $\mathrm{SnO}_{2} / \mathrm{S}$

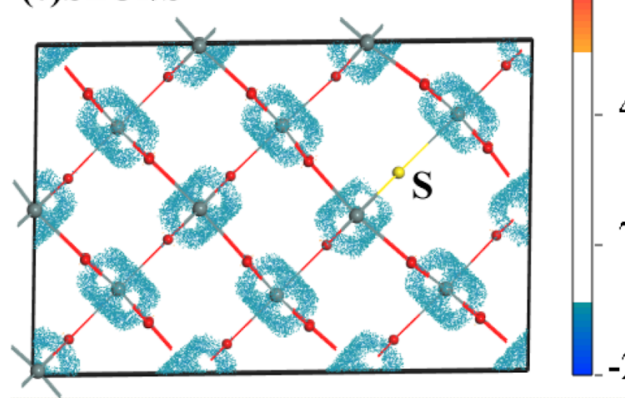

$8.120 \mathrm{e}-1$

$4.448 \mathrm{e}-1$

$7.758 \mathrm{e}-2$

$-2.896 \mathrm{e}-1$

Figure 3: Differential charge density of $\mathrm{SnO}_{2}$ with $\mathrm{O}$ atom substituted by non-metal element.

late charge is reduced. This provides more electrons as free carriers, making the system appear metallic. The analysis result is consistent with the analysis result of the energy band structure.

\section{Optical properties}

$\mathrm{SnO}_{2}$ is widely used as a transparent conductive film material, especially in doors and windows, it is also preferred for coatings of low-emissivity glass. The most important property of low-emissivity is the reflectivity in the infrared region. According to the reflectance spectrum of the material, a good adiabatic behavior of the material requires the plasma frequency to be close to the visible region. Plasma is a system in which the dielectric constant is $\varepsilon_{\mathrm{r}}=0$, the concentration of positive and negative charges is the same, and positive and negative charges are free to move. When the probability of collision of free electrons in a solid is 0 , the dielectric function is

$$
\varepsilon_{\mathrm{r}}(\omega)=1-\frac{\omega_{\mathrm{p}}^{2}}{\omega^{2}}, \text { with } \omega_{\mathrm{p}}^{2}=\frac{\mathrm{Ne}^{* 2}}{\mathrm{~m} \varepsilon_{0}}
$$

where $\omega_{p}$ is the plasma frequency. $\omega_{p}$ is the intrinsic characteristic frequency of the material. The plasma oscillation frequencies vary for different crystal materials. In general, it is proportional to the concentration of free electrons. When the vibration frequency of the incident light is greater than the plasma oscillation frequency, the crystal material is transparent. Otherwise, it 
is impossible for the light to pass through, showing metallic reflectivity.

The reflectance spectra of $\mathrm{SnO}_{2}$ crystals doped with non-metal elements are shown in Figure 4. It shows that $\mathrm{SnO}_{2}$ doped with F had the highest reflectance, followed by doping with $\mathrm{N}, \mathrm{C}, \mathrm{S}$, and $\mathrm{B}$ in this order. When the wavelength of light is greater than $1800 \mathrm{~nm}$, the material shows metallic reflectivity, when the wavelength is below $1800 \mathrm{~nm}$, the material shows transparency. Therefore, F-doped $\mathrm{SnO}_{2}$ is the most suitable material for lowemissivity glass coatings.

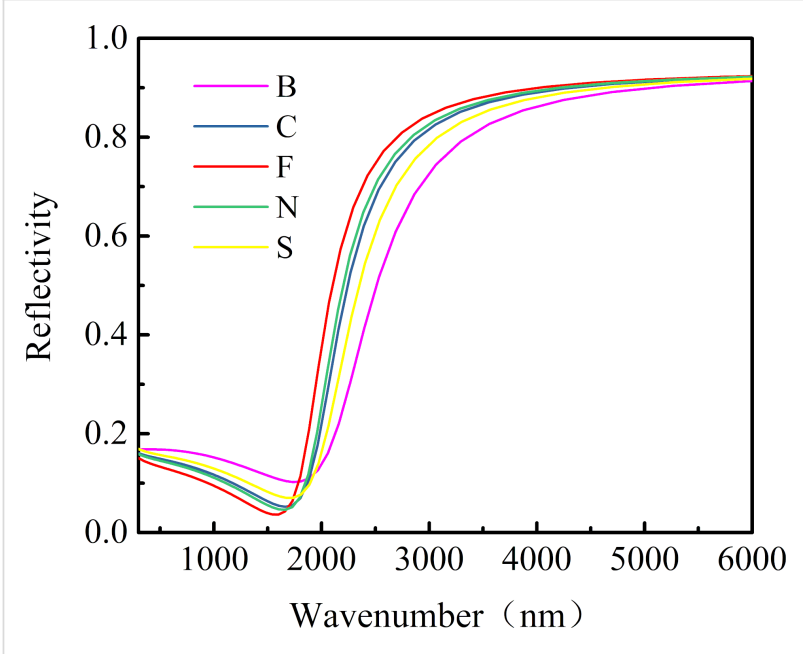

Figure 4: The reflection spectrum of $\mathrm{SnO}_{2}$ of $\mathrm{O}$ atom replaced by nonmetal atom.

\section{Conclusion}

Based on first-principles density functional theory, crystal structure, electronic structure, and optical properties of $\mathrm{SnO}_{2}$ doped with non-metal elements were theoretically analyzed. The calculation results confirm that the doping caused the crystal lattice to expand. The F-doped $\mathrm{SnO}_{2}$ lattice has the lowest binding energy and is prone to replacement doping. S-doping forms p-type semiconductors, and F-doping forms n-type semiconductors. The optical analysis results revealed that F-doped $\mathrm{SnO}_{2}$ possesses the highest reflectivity in the infrared region, and is most suitable as a low-emissivity coating material.

\section{Acknowledgements}

The numerical calculations in this paper have been carried out at the computing system of the Graphene Application Technology Tangshan Public Service Platform.

\section{Funding}

This work was supported by the National Key Research and Development Program of China (No. 2016YFB0303902), the National Natural Science Foundation of China (No. 51602278), the Key Basic Research Project of Hebei Province (No. 17961109D), and the Natural Science Foundation of Hebei Province (No. E2016203149).

\section{ORCID ${ }^{\circledR}$ iDs}

Jianyuan Yu - https://orcid.org/0000-0002-5632-2661

\section{Preprint}

A non-peer-reviewed version of this article has been previously published as a preprint: https://doi.org/10.3762/bxiv.2020.68.v1

\section{References}

1. Reshmi Krishnan, R.; Kavitha, V. S.; Santhosh Kumar, M. C.; Gopchandran, K. G.; Mahadevan Pillai, V. P. Mater. Sci. Semicond. Process. 2019, 93, 134-147. doi:10.1016/j.mssp.2018.12.029

2. Huo, X.; Jiang, S.; Liu, P.; Shen, M.; Qiu, S.; Li, M.-Y. CrystEngComm 2017, 19, 4413-4423. doi:10.1039/c7ce00705a

3. Untila, G. G.; Kost, T. N.; Chebotareva, A. B. Sol. Energy 2018, 159, 173-185. doi:10.1016/j.solener.2017.10.068

4. Seo, S.; Jeong, S.; Park, H.; Shin, H.; Park, N.-G. Chem. Commun. 2019, 55, 2403-2416. doi:10.1039/c8cc09578g

5. Zhao, G. Y.; Zhi, X.; Ren, Y.; Zhu, T. Mater. Sci. Forum 2009, 620-622, 5-8. doi:10.4028/www.scientific.net/msf.620-622.5

6. Dang, H. P.; Luc, Q. H.; Nguyen, T. T.; Le, T. J. Alloys Compd. 2019, 776, 276-286. doi:10.1016/j.jallcom.2018.10.272

7. Du, W.; Si, W.; Du, W.; Ouyang, T.; Wang, F.; Gao, M.; Wu, L.; Liu, J.; Qian, Z.; Liu, W. J. Alloys Compd. 2020, 834, 155209. doi:10.1016/j.jallcom.2020.155209

8. Duong, A. Q.; Dang, H. P.; Le, T. J. Photochem. Photobiol., A 2020, 390, 112334. doi:10.1016/j.jphotochem.2019.112334

9. Nguyen, T. T.; Dang, H. P.; Luc, Q. H.; Le, T. Ceram. Int. 2019, 45, 9147-9156. doi:10.1016/j.ceramint.2019.01.255

10. Majumder, R.; Kundu, S.; Ghosh, R.; Roy, S.; Guria, U.; Chowdhury, M. P. Appl. Nanosci. 2019, 9, 1553-1563. doi:10.1007/s13204-019-01047-9

11. Ching-Prado, E.; Watson, A.; Miranda, H. J. Mater. Sci.: Mater. Electron. 2018, 29, 15299-15306. doi:10.1007/s10854-018-8795-8

12. Ching-Prado, E.; Samudio, C. A.; Santiago-Aviles, J.; Velumani, S. J. Mater. Sci.: Mater. Electron. 2018, 29, 15423-15435. doi:10.1007/s10854-018-9067-3

13. Li, W.; Ding, C.; Li, J.; Ren, Q.; Bai, G.; Xu, J. Appl. Surf. Sci. 2020, 502, 144140. doi:10.1016/j.apsusc.2019.144140

14. Zhang, G.; Qin, G.; Yu, G.; Hu, Q.; Fu, H.; Shao, C. Thin Solid Films 2012, 520, 5965-5970. doi:10.1016/j.tsf.2012.04.049

15. Shi, L.-B.; Dong, H.-K.; Qi, G.-Q. J. Magn. Magn. Mater. 2013, 345 , 215-221. doi:10.1016/j.jmmm.2013.06.052

16. Bakht, K.; Mahmood, T.; Ahmed, M.; Abid, K. Superlattices Microstruct. 2016, 90, 236-241. doi:10.1016/j.spmi.2015.12.021

17. Li, X.; Deng, R.; Li, Y.; Yao, B.; Ding, Z.; Qin, J.; Liang, Q. Ceram. Int. 2016, 42, 5299-5303. doi:10.1016/j.ceramint.2015.12.059

18. Guo, D.; Hu, C. Appl. Surf. Sci. 2012, 258, 6987-6992. doi:10.1016/j.apsusc.2012.03.149

19. Dolbec, R.; El Khakani, M. A.; Serventi, A. M.; Trudeau, M.; Saint-Jacques, R. G. Thin Solid Films 2002, 419, 230-236. doi:10.1016/s0040-6090(02)00769-1 
20. Stashans, A.; Puchaicela, P.; Rivera, R. J. Mater. Sci. 2014, 49, 2904-2911. doi:10.1007/s10853-013-7999-9

\section{License and Terms}

This is an Open Access article under the terms of the Creative Commons Attribution License (https://creativecommons.org/licenses/by/4.0). Please note that the reuse, redistribution and reproduction in particular requires that the authors and source are credited.

The license is subject to the Beilstein Journal of Nanotechnology terms and conditions: (https://www.beilstein-journals.org/bjnano)

The definitive version of this article is the electronic one which can be found at:

https://doi.org/10.3762/bjnano.11.116 